\title{
The New Public Management and Stakeholders theory applied to the territorial intelligence.
}

\author{
LAAMRANI EL IDRISSI Safae, TAOUAB Omar. \\ PhD Student, Professor. \\ ENCGK - Université Ibn Tofaïl Kenitra, Morocco
}

\begin{abstract}
In the context of territorial intelligence, territorial actors and, in large part, public administrations in particular are in constant development.

For this reason and to support territorial development, several theories and practices have been adopted.

Among the theories developed to carry out the function of territorial governance, we find the stakeholder theory that comes to put in place a strategy centered on the systems of corporate governance.

Thus, the NPM also appears as a new management tool, considered as a "hybrid, processual and evolutionary construct" or/and as a slippery label.

The present article aims to conduct a literature review of the above mentioned theories in order to identify the advantages and disadvantages of each.
\end{abstract}

Keywords: Territorial intelligence; Territorial actors; Stakeholders; New Public Management.

\section{Introduction}

For several years, we have seen a strong emergence of Stakeholders theory as well as the New Public Management practices. These, are at the heart of current debates on the role of territorial actors.

Before starting our review of literature about the New Public Management and Stakeholders theory, we briefly discuss the concept of territorial intelligence, which lies at the heart of the subject of this article.

The multiplicity of senses and functions, or even uses, of the notion of territorial intelligence explains its global diffusion and its success in discourse, but it is an obstacle to its use in a scientific reflection. Yet today, it has become so obvious that it is almost impossible to ignore it, thanks to this new attention to the territories is today, which probably explains the emergence and the reason to be of the notion of territorial intelligence [1].

Scientists and professionals have never found a single definition of territorial intelligence, but they have come up with two approaches to defining this concept.

- Downward approach
In its institutional version, IT is part of a more global approach that confers its legitimacy and defines its field of action. One of the strong features of this approach is that it takes the nation's only relevant scale of application in the international geo-economic context. Thus, the territory as a meso-economic entity has no role as such. It is envisaged, on this scale, only as a space of application of a deconcentrated policy of economic intelligence. Moreover, representatives of this approach use the term "economic intelligence applied to the territory" rather than IT.

On an administrative level, the territorial application of the economic intelligence policy is coordinated by each regional prefecture and must result in a "regional economic intelligence scheme", based on the creation of new bodies responsible for implementing at the local level, the national EI system [2].

On an economic level, the territorial application of economic intelligence is only a variation, at the local level, of IE's policy of restoring the competitiveness of the nation.

Such a policy can also support the setting up of public-private partnership networks with the aim of improving the flow of strategic information from the first to the second. It must encourage 
them to protect their heritage. In this respect, it is interesting to highlight the look that the Mongereau report takes on the competitiveness clusters. The latter are indeed an illustration of a territorial application of a policy of economic intelligence for two reasons: on the one hand, by encouraging businesses to network and on the other hand to make them aware of new threats informing them to install systems for securing their assets.

\section{- the bottom-up approach}

Indeed, it is a concept with two facets, an alternative approach of territorial intelligence has developed in parallel and without ever really cross the path of the first. It must be said that they each have different places of birth. The first approach was built mainly in the institutional field, while the second emerged in the academic field combining research from economics, geography, information and communication science and technology, and research. Knowledge management [3].

On the surface, both are joined by advocating the importance in today's society, using the entire tools palette today to collect, treat and recover the information. Information is now a strategic resource for the company and its competitiveness but also for the region and its development. However, territorial information systems (TIS) are and will remain a tool in the service of an approach of the territory and its development. It is at this level that the differences appear $^{1}$.

The IT draws its roots and is deployed, as a concrete approach, in the approach of territorial development presented above. Like the proponents of territorial development, the IT representatives emphasize the "methodological" need to make all the individuals included in the territory the key players in a successful local development dynamic. The logic of this form of development is based on two strong hypotheses.

The first affirms that territorial development must be endogenous, that is to say, secreted by the actors themselves through local initiatives in the form of projects. These different projects, resulting in the development of built resources, are the result of coordination logic that are not exclusively those of the market nor that of a state regulation.

This is the argument at the heart of the second hypothesis. The originality of such a position is to introduce a third mode of coordination between the actors of the territory, complementary to the other two in its contribution to development. Thus, as Pecqueur emphasizes « il s'agit de mettre en évidence une dynamique qui valorise l'efficacité des relations non exclusivement marchandes entre les hommes pour valoriser les richesses dont ils disposent $\gg(2000$, p. 13) wich means "It is a matter of highlighting a dynamic that values the effectiveness of the nonexclusively market relations between men to value the wealth they have". This new mode of coordination is based on the collective learning abilities of the players in this area.

Thus, regardless of the systems of territorial intelligence (STI) implemented, all are part of an approach based on a participative mode of governance based on bottom-up logic. The IT is not limited to a territorial monitoring system. It is a process of information and territorial communication, of creation of innovative territorial contents likely to favor the collaboration and the adhesion around new projects.

Territorial Information Systems (TIS) make it possible to create a learning environment that is conducive to endogenous territorial development by offering the possibility of sharing and disseminating multiple and transdisciplinary knowledge [5].

The downward approach does not consider the territory as a relevant field. In this approach, the territory is only a receptacle, a uniform field of application, a national policy of economic intelligence. Conversely, the diversity of territories is posited as a prerequisite for any IT approach in the bottom-up approach. The latter represents an essential lever of development where territorial actors play a key role in the development of reconstructed resources specific to each territory. A successful territorial dynamic is an endogenous dynamic.

The first approach speaks little about development, preferring the notion of competitiveness-attractiveness. Economic and territorial intelligence is a strategic tool to restore 
the nation's competitiveness by making the territories that make it up more competitive. In its second version, territorial intelligence is at the service of a balanced and sustainable development specific to each territory. Thus, the success of a territory depends more on its capacity to develop diversified projects, build a formal capital by appealing to the territorial actors in a logic of partnership, and not its capacity of attraction. In this perspective, the wealth of TIS is to offer tools promoting networking, information sharing and cooperation between actors. The prospects are definitely not the same.

In the context of this article based on the concept of territorial intelligence, it is important to discuss the theories dealing with the subject. For this, we have chosen two theories, namely stakeholder theory and the new public management.

\section{The Stakeholder theory}

The concept of stakeholder was first mobilized in strategy before becoming essential in the reflections centered on corporate governance systems (Blair 1995, Charreaux 1997, 1999, Charreaux and Desbrières 1998; Wirtz, 1999, Special Reports in Management, Vol 23, No. 3, 1998 and in the 2000 edition of the Moral Report on Money in the World).

This theory is interested in "the study of organizational-stakeholder relations and contributes to the foundation of a relational model of the organization. But one of the problems of its evolution is the confusion sometimes made between its nature and its objective [6].

This concept of stakeholder "was mobilized also in strategy before becoming essential in the reflections centered on the systems of corporate governance $^{2,}$.

Today, Organizational Stakeholder Theory has become a theoretical reference in AngloSaxon literature and is positioned as an alternative to the contractual theories of organizations (agency theory and economics of transaction) to reformulate the theory of the firm.

It is also "a managerial theory and a normative theory in organizational ethics, which often leads to a combination of these two dimensions.

The main objective of the Stakeholder Theory is thus to broaden the representation that management sciences have of the role and responsibilities of leaders: beyond the function of profit maximization, it is important to include in the governance of the business interests and rights of non-shareholders [8].

In the original definition of the Stanford Research institute (1963), the concept of Stakeholder designated the groups essential to the survival of the enterprise. This meaning is very similar to that of Rhenman and Stymne (1965) for whom a PP is a group that depends on the company to achieve its own goals and on which the latter depends to ensure its existence. Since then, definitions have multiplied and can be placed in a continuum from the broadest to the most restricted (see Michell et al., 1999, 858, Martinet, 1984: 74).

The most commonly used definition (which gives the term Stakeholder the broadest meaning) is that proposed by Freeman (1984: 46), and in particular by Carroll and Buchholtz (2000: 66): stakeholder is an individual or group of individuals who can affect or be affected by the achievement of organizational objectives. «In this vision, Stakeholders designate suppliers, customers, employees, investors, community, etc.

However, it is important to note that stakeholders are different. Mitchell et al. (1997) identified 7 types of Stakeholders according to whether they have one, two or all three attributes: the power to influence organizational decisions, the degree of legitimacy in business relations, the urgency of the rights that the Stakeholder can claim to exercise on the company.

However, it considers that there is a reciprocal interdependence between all the PPs, so the TPP must be placed in a context of multilateral relations (see also, Rowley, 1997: 890). In the same way, the relations between the organization and its PPs can very well evolve very quickly, it is advisable to introduce a dynamic aspect in the identification of the PP (Frooman 1999, Kochan and Rubinstein, 2000, p.369). 
According to Donaldson and Preston (1995), stakeholders are defined by their legitimate interest in the organization. This implies that:

Stakeholders are groups and people with legitimate interests. They are known and identified; the interests of all stakeholder groups have intrinsic value.

In this sense, Carroll (1995) distinguishes between: primary PPs that have a formal, official or contractual relationship with the organization and other secondary PPs. Pelle-Culpin (1998) proposes, based on the three dimensions of social responsibility, the following classification:

- Institutional stakeholders: from laws, regulations, and interorganizational bodies or industry-specific professional bodies;

- Economic stakeholders: the different types of actors operating in the markets in which the company is positioned;

- Ethical stakeholders: organizations of ethical pressure. Based on the theory of social differentiation developed by Archer (1996), Friedman and Miles (2002) distinguish between four groups of stakeholders.

They consider that the relations between organization and stakeholders can be, on the one hand, compatible or not compatible with the interests of the company and, on the other hand, necessary (internal) or contingent (external). Thus, they distinguish between:

- Necessary and compatible relationships: shareholders, management, partners;

- Necessary but incompatible relationships: unions, employees, government, customers, suppliers, lenders, organizations;

- Contingent and compatible relations: public in general, organizations connected in common associations;

- Contingent but incompatible relations: ONG Pesqueux (2002) proposes a classification close to that of Carroll but clearer on the stakeholders:

- Contractual stakeholders, which concern actors in direct and contractually determined relationships, as its name suggests with the company such as customers, suppliers, staff and shareholders.

- The diffuse stakeholders, which concerns the actors located around the company who can affect or be affected by the company without being in a contractual ${ }^{3}$ relationship such as public authorities, local authorities, associations and NGOs and the public opinion.

It should be noted that the network of relationships that is established between the organization and its stakeholders is extensive and complex.

Extended, because a large number of Stakeholders are concerned. Complex, because there are or can be different types of relationships between the various stakeholders. Stakeholder theory is concerned with the study of the nature of the relationships that connect the organization with its different stakeholders. Its scope and its different approaches will be presented in the following paragraphs.

According to Torre (2011), the actors: "obviously understand the public authorities, whether they are deconcentrated services of the State or local public authorities. But we must now add to these traditional protagonists of governmentality, the role played jointly by different stakeholders, private or semi-public, in the process of coordination and action plans in the service of the territories. It is the question of participatory democracy that arises, and the involvement of many local actors in a decisionmaking process that is no longer left only in the hands of the state.

Territorial intelligence is at the crossroads of different theories. Based on stakeholder theory in its organizational aspect, it places the participation, cooperation and involvement of the various actors in public management as an important mechanism for achieving territorial development.

In this context, Fernandez's (2017) Stakeholder Theory is considered a model of participatory governance in that its design is based on constructive negotiation while ensuring that each stakeholder has an interest in cooperating with others. 
In addition, the systemic structuring of the territory is organized in a game of systematic interaction between the territory and all the actors who organize a mode of territorial intelligence resulting from the collective action. Collective action, public or not, is necessarily perceived in a project logic that is organized around stakeholder relations.

These relationships remain the key word for the success or failure of the collective project and it is important to have a very clear vision of the positions of the actors around the project. But, beyond this position, stakeholder theory allows, by analogy, to reposition this dynamic of actors around the collective project according to its articulation which is based on the degree of adhesion / opposition and the level of involvement (Vaesken and Zafiropolou, 2008).

Thus, in a territorial intelligence approach inviting various actors to collective action of development projects, several researchers have used this theory in the analysis of their work, such as Belkaid (2014) which shows the relevance of its application to territorial studies.

\section{The contribution of the NPM}

The NMP has taken the place of many unfinished reforms and attempts at modernization of the public sector, "indeed the fiscal techniques introduced in the 1960s were aimed at better use of public funds. Once the objectives of the projects were defined, they focused on their evaluation through cost-benefit or costeffectiveness studies. Theoretically, however, these mechanisms have faced many obstacles in their application, mainly because of their complexity"[10]

From a theoretical point of view, "the NMP is a concept that draws its foundations from many currents of thought (neoclassical current, theory of organizations, agency theory, property rights theory, etc.) and which by many aspects is linked to the ideology of Public Choice based on methodological individualism, the use of privatization and greater flexibility and decentralization of administrative units".

The fundamental idea of the NPM is that the techniques used in private sector management are more advanced than those in the public sector and can be applied to it. Indeed, the public sector considered inoperative, excessively bureaucratic, rigid, expensive, centered on its own development (Leviathan effect), non-innovative and having a hierarchy too centralized.

The NPM appears as "a hybrid, processual, and evolutionary construct" (Eymery-Douzans, 2008, p.80) or as a slippery label (Manning, 2000, in Dunleavy et al., 2006), to the point that any innovation in management the public sector could claim it. This is evidenced by the two-level analysis proposed by Dunleavy et al. (2006).

At the first level are the main ideas of the NPM, imported from management practices and the theory of public choice: disaggregation, competition and incentive. Disintegration aims to break up the monolithic hierarchies that characterize large public administrations into autonomous, less hierarchical structures; these new structures call for a redefinition of management and information systems. Introducing competition in public structures should lower the cost and improve the quality of services offered. In terms of incentives, the NPM replaces the incentive and incentive system based on the public sector ethos with a system of financial incentives linked to specific performance.

At the second level, there is a proliferation of ideas, specific inventions born from the application of new economic and managerial principles of the NPM in response to issues specific to the public sector. These new practices, which have helped to expand the NPM wave and shape it, owe their success to the connections that could be made with the ideas of the first level. In the words of the authors: "A key part of the appeal of these second level changes has also been that they have a wider reformation and gain in intellectual coherence from their link with the higher order ideas" (Dunleavy et al., 2006, p. 470). Among these practices, in relation to disaggregation, we note the following: agencification, decoupling of political systems, improvement of performance measurement; in relation to competition: outsourcing, deregulation, quasi-markets, liberalization of the product market; in relation to the incentive: privatization of capital, public-private partnerships, linkage of remuneration to performance. Seen from the perspective of the state's functions, the NPM is transdisciplinary: it affects both the strategic, 
finance, marketing and human resources functions (Amar and Berthier, 2007). "The NPM pushes the state to question its role and its missions, those it must ensure, those it can delegate or entrust to agencies or private companies and those it can organize in partnership with the private sector "(Amar and Berthier, 2007, p.3).

It is indeed a public management method that borrows methods and tools from the private sector, based on the search for performance and results (Osborne and Gaebler, 1993). The concepts underlying the borrowing of such tools are those of flexibility, efficiency, efficiency and evaluation. Gilbert (1998) defines the management tool or tool as "any conceptual or material means, with structuring properties, by which a manager, pursuing certain organizational goals in a given context, implements a management technique". This management tool standardizes behaviors in the sense that it tends to make them conform to the tool, reveals the essential determinants of the organization and helps actors to imagine new patterns, facilitates the introduction of change through a construction progressive shared representation and facilitates the transformation of the rules[11]

We consider that the tool is not neutral in essence and purpose but that it is based on social, cultural and organizational data that condition it. Outiller allows to modify the representations that determine a collective action and to initiate collective learning processes. This raises the question of the legitimacy of the management model adopted by the stakeholders of public organizations, be they users, citizens, taxpayers, politicians, public officials or senior executives of the public sector. The tool is not an end in itself and its legitimacy is linked to its use (El Bahri, 2015).

The ideas and practices promoted by the NPM have certainly encouraged positive changes within public administrations, including the opening up of new professional knowledge and new management tools (Piraux, 2012b). However, the record is mixed. Recent studies challenge the NPM's initial postulates; stress the weakening of public ethics - valuing the general interest - in favor of market values - efficiency and effectiveness - highlight the difficulties of applying the new rules. Managerial practices, in particular because of individual and collective resistance and lack of resources, denounce certain negative indirect effects that may counterbalance the expected effects, or show a return of bureaucracy.

The adoption of the NPM principles has a very profound impact on the characteristics of control and accountability between the government and the executive agencies.

Concretely, the NPM requires the implementation of new instruments of management and supervision of the activities of the public services henceforth oriented towards efficiency and performance. Among these, the contractualization of relations between the principal (the political authority) and the agent (executing agency) is one of the tools inextricably linked to the NPM (Verhoest, 2003). Contractualization consists in setting in a contract control and incentive mechanisms aimed at reducing the costs related to the conflicts of interest existing between the two actors and maximizing the utility of each one. The management contract or performance contract thus becomes a new cog in public action. The key problem becomes that of determining an optimal contract for both parties.

From theory to practice, there is a big step. Contracting does not completely solve the problem of control. In fact, the contracts binding the agencies and the government are long-term contracts, which are in essence still incomplete; leaving agency heads wide areas of autonomy, they do not offer an absolute guarantee against opportunistic behavior.

The proliferation of specialized agencies has led to silosation, ie fragmentation, of the public sector, a lack of clarity in the organizational system, and a growing difficulty in coordinating more and more organizations. more diversified. The means that should support this coordination are, in fact, insufficient: first, the obligation to sign a contract is not binding on all autonomous bodies; secondly, the information provided by the agencies is heterogeneous, of variable quality, non-standardized, and therefore unsuitable for rigorous aggregation; Finally, there is a lack of dedicated staff in the central services to coordinate the activities of the agencies. 
Difficulties in agency oversight and policy coordination have hampered the development of agencies in many countries, including those that were initially most supportive of NPM principles such as the UK or New Zealand. Government concerns now appear to be more focused on policy coherence and coordination: the focus is on horizontal collaboration, integrated service delivery between agencies and levels of government, clustering of departments and reintegration, standardization of agencies (OECD, 2002, Verhoest et al., 2007).

The establishment of the NPM has given rise to multiple individual or collective resistance. First of all, because civil servants perceive risks on their remuneration (less favorable evolution, disappearance of guarantees, etc.); on their recognition; on their protection; and finally their autonomy (fear of a loss of independence).

Thus, although having more freedoms than in the past, public managers as a whole do not have the leeway of the private sector and the resulting remuneration. In addition, the NMP has sometimes resulted in an increase in conflicting relationships.

\section{Conclusion and recommendations}

As a conclusion, we can say that each practice and theory has advantages and disadvantages, as is the case for stakeholder theory and for new public management.

The stakeholder theory is a theory that seeks to replace the shareholder view of the firm, and thus to ensure good performance it is important to take into account the interests of stakeholders visà-vis the organization, and this, in order to keep an intrinsic value of the interests of these stakeholders and leave no interest to dominate in detriment of others.

\section{References:}

[1] BEATE KOHLER-KOCH ET RAINER EISING (eds.),(1999) The Transformation of Governance in the European Union, London, ROUTLEDGE.

[2] Maud Pelissier et Isabelle Pubourdin, (2009/4) l'intelligence économique, Lavoisier (Vol 5)

[3] Yvon Pesqueux. (2017) Robert E. Freeman et la théorie des parties prenantes en question. Master. France.
While the practices of the new public management have as their main vocation to introduce entrepreneurial spirit in the public sector, seeking an efficiency in the use of available public resources. Indeed, this can only be achieved through a separation of strategic decision-making, which is the responsibility of political power, of operational management belonging to the administration and the development of decentralization, especially functional certain strategic autonomy to public organizations vis-à-vis their trusteeship. It is also necessary to include the perspectives of the new governance, which modifies the way in which the strategies of the public organizations are elaborated which are articulated on common projects carried by multiple public or private stakeholders which share in common the development of public policies.

But the combination of the means available to each of these practices and theories discussed throughout our article can be interesting for the organization and for the territorial actor in a general way, can also carry out the practices of the new governance (termed good governance).

This can be achieved from our modest point of view through:

- The actual introduction of the entrepreneurial spirit into the public sphere;

- Efficient use of available resources while introducing stakeholders in decisionmaking;

- Establishment of a territorial intelligence system based on stakeholder theory based on the dimensions and practices of new public management.

[4] Jean Jacques Girardot, (Mai 2004) intelligence territoriale et participation, $3^{\text {ème }}$ rencontre «TIC et territoires : quels développement ? » de Lille, Article $\mathrm{N}^{\circ} 161$.

[5] EL KHAZZAR Aziz, Gouvernance et Approche Territoriale : Pour une Nouvelle Strategie de Développement.

[6] Anne-Cécile Douillet, Logiques de constitution des espaces de développement promus par les politiques de 
développement territorial, Le territoire objet de politiques publiques, p. 39-54.

[7] Mohamed Torra, (2013/2) « Territoire comme espace d'attractivité et de déclinaison de l'intelligence économique en intelligence territoriale », Marché et organisations $\left(\mathrm{N}^{\circ} 18\right)$, p. 67-85.

[8] Béatrice Van Haeperen, (2012/2) «Que sont les principes du New Public Management devenus ? Le cas de l'administration régionale wallonne », Reflets et perspectives de la vie économique (Tome LI), p. 83-99.

[9] Pierre-Charles Pupion, (2016/3) « L'esprit du NPM et les organisations publiques », Gestion et management public (Volume 5 / $\left.\mathrm{n}^{\circ} 1\right)$.

[10] Pierre-Charles Pupion, Yves Chappoz (2015/3) «L'outil de gestion au service du NPM », Gestion et management public (Volume $4 / \mathrm{n}^{\circ} 1$ ). 